\title{
São José dos Quatro Marcos-MT e a instalação da Escola Rural Mista Duque de
} Caxias (1966-1972)

São José dos Quatro Marcos and the Installation of Duque de Caxias Mixed Rural School (19661972)

São José dos Quatro Marcos y la Instalación de la Escuela Rural Mista Dusque de Caxias (19661972)

\section{Resumo}

Este trabalho objetiva trazer a lume o movimento inicial dos agricultores e de suas famílias para a criação de uma escola em São José dos Quatro Marcos - MT para a escolarização de seus filhos, bem como a forma pela qual foi organizada por seus primeiros professores. A pesquisa tem como referencial teórico metodológico a perspectiva da História Cultural (Chartier, 1991) e das Instituições Escolares (Sanfelice, 2007). Para tal, utilizamos documentos encontrados no Arquivo Público de Cáceres, tais como periódicos e contratos, pesquisa sobre colonização recente e obras memorialistas. A delimitação temporal (1966-1972) justifica-se pela criação da Escola Mista Duque de Caxias e o período no qual os docentes Inivaldo Mila e Maria Luiza permaneceram na condução da escola. Concluiu-se que, naquela realidade, a escola se tornou prioridade para garantir a permanência em áreas de colonização recente, pois, sem oferecer educação escolar aos filhos dos migrantes, as famílias não permaneceriam em suas terras. Por isso, não mediram esforços para erigi-la em meio a mata.

Palavras-chave: São José dos Quatro Marcos; Escola; Educação-Mato Grosso; Colonização recente.

\begin{abstract}
This work aims to bring to light the initial movement of farmers and their families to create a school in São José dos Quatro Marcos - MT for the schooling of their children, as well as the way in which it was organized by their first teachers. The research has as methodological theoretical referential the perspective of Cultural History (Chartier, 1991) and School Institutions (Sanfelice, 2007). To this end, we used documents found in the Public Archives of Cáceres, such as periodicals and contracts, research about recent colonization and memorial works. The temporal delimitation (1966-1972) is justified by the creation of Duque de Caxias Mixed School and the period in which the teachers Inivaldo Mila and Maria Luiza were in charge of the school. It was concluded that in, that reality, the school became a priority to guarantee the permanence in areas of recent colonization, because, without offering school education to the children of the immigrants, the families would not remain in their lands. Therefore, they spared no effort to build it in the middle of the forest.
\end{abstract}

Keywords: São José dos Quatro Marcos; School; Education-Mato Grosso; Recent colonization.

\section{Resumen}

Este trabajo tiene como objetivo mostrar el movimiento inicial de los agricultores e sus familias para crear una escuela en São José dos Quatro Marcos - MT para la escolarización de sus hijos, así como la forma por la cual fue organizada por sus primer profesores. La pesquisa tiene como referencial teórico metodológico la perspectiva de la Historia Cultural (Chartier, 1991) y de la Instituciones Escolares (Sanfelice, 2007). Para esto, utilizamos documentos encontrados en el Archivo Público de Cáceres, como periódicos y contratos, pesquisa sobre colonización reciente y obras memorialistas. La delimitación temporal (1966-1972) se justifica con la creación de la Escuela Mista Duque de Caxias y el período en que las maestras Inivaldo Mila y Maria Luiza permanecerán a cargo de la escuela. Se concluyó que, en esa realidad, la escuela se tornó prioridad para garantir la permanencia en áreas de colonización reciente, ya que, sin ofrecer educación 
a los niños de los migrantes, la familias no permanecerían en sus tierras. Por lo tanto, no escatimaron esfuerzos para construirla en medio del bosque.

Palabras clave: São José dos Quatro Marcos; Escuela; Educación-Mato Grosso; Reciente colonización.

\section{Introdução}

A cidade de São José dos Quatro Marcos foi criada no bojo do processo de colonização recente ${ }^{1}$ de Mato Grosso, advindo de um programa gestado por Getúlio Vargas com vistas a ocupar os "espaços vazios” na Amazônia², destacando a importância de integrá-la ao restante do país. Para tal, argumentava sobre a necessidade de investimentos em infraestrutura e numa política de povoamento dessa parte do país. Com esse objetivo, criou o programa "marcha para o oeste" com o discurso de que era necessário reocupar essas áreas levando a modernização e o progresso a essa parte do Brasil.

Foi no âmbito do discurso de ocupação dos "espaços vazios" que as terras onde hoje se encontram os municípios de Mirassol d'Oeste e São José dos Quatro Marcos foram vendidas e reocupadas por trabalhadores rurais das regiões sul e sudeste, os quais, não possuindo recursos para adquirir terras em sua região de origem, se aventuravam a ocupar essas áreas, ainda em mata nativa onde havia tudo por fazer, inclusive a escola.

Nesse sentido, o presente trabalho tem como objetivo trazer a lume o movimento inicial dos agricultores e suas famílias para a criação de uma escola em São José dos Quatro Marcos para ensinar aos seus filhos ${ }^{3}$, compreendendo que "não há instituição escolar ou educativa que não mereça ser objeto de pesquisa [...]. O desafio é trazer à luz esse sentido e, com frequência há boas surpresas" (Sanfelice, 2007, p. 79).

\section{Metodologia}

A pesquisa tem como referencial teórico metodológico a perspectiva da História Cultural (Chartier, 1991) e das Instituições Escolares (Sanfelice, 2007). Para tal, utilizamos documentos encontrados no Arquivo Público de Cáceres, tais como periódicos e contratos, pesquisa sobre colonização recente e obras memorialistas. A delimitação temporal (1966-1972) justificase pela criação da Escola Mista Duque de Caxias e o período no qual os docentes Inivaldo Mila e Maria Luiza permaneceram na condução da escola.

\section{Instituição Escolar em Área de Colonização Recente}

Paulo Mendonça, paulista da cidade de Mirassol, proprietário da Imobiliária Mirassol em São Paulo, adquiriu no início dos anos de 1960, a preços irrisórios, 50 mil hectares de mata fechada a uma distância aproximada de 50 quilômetros da cidade de Cáceres. A intenção não era ficar com a terra, mas repassá-las a fim de lucrar com o investimento.

Assim, criou uma cidade em meio a floresta para possibilitar a estrutura necessária para facilitar a revenda dessas terras, em pequenos lotes, a trabalhadores do interior de São Paulo. Essa cidade recebeu o nome de Mirassol d'Oeste, uma homenagem a cidade de Mirassol no estado de São Paulo onde Mendonça residia. Mendonça explica que, para atrair compradores, só fez propaganda para moradores da sua região: "Eu tinha naquela época uma equipe de corretores que eu dava uma lotação, uma

\footnotetext{
${ }^{1}$ Conforme Oliveira (2017, p. 74), “[...] colonização recente foi à reocupação dos espaços geográficos, a partir da segunda metade do século $\mathrm{XX}$, anteriormente ocupado por diferentes populações indígenas. Esta colonização realizada por migrantes de diferentes estados do Brasil foi ao longo desse período, até o final do século XX, sendo socialmente produzida".

${ }^{2}$ A Amazônia compreende a região Norte - estados de Rondônia, Acre, Amazonas, Roraima, Amapá, Pará e Tocantins - e parte do Centrooeste - Mato Grosso. A outra referência ao território amazônico, que se define como Amazônia Legal (criada pelo Plano de Valorização da Amazônia - 1953), inclui o oeste do Maranhão (Guimarães Neto, 2005, p. 545).

${ }^{3}$ Pesquisa com financiamento da SEDUC-MT.
} 
komby. Com capacidade para carregar dez pessoas. E esses indivíduos andavam naquela região de lá de São Paulo. Eu não andei fora da minha região, eu não fiz propaganda [...]" (Heinst, 2003, p. 58).

Conforme depoimento, foi por meio de sua Imobiliária que centenas de famílias de trabalhadores rurais, em sua maioria arrendatários e pequenos sitiantes do interior de São Paulo, compraram terra em Mato Grosso, distanciando-se de amigos e parentes para se embrenhar rumo ao novo, ao inesperado, sonhando encontrar a prosperidade que o solo paulista não lhes proporcionara até então.

Dentre os muitos migrantes que se mudaram nas proximidades de Mirassol d'Oeste, encontravam-se Zeferino José de Souza, Luiz Barbosa e Miguel Barbosa do Nascimento, que doaram 11,02 alqueires a fim de criar um núcleo populacional nas proximidades do então povoado de Mirassol. Utilizaram quatro pedaços de madeira como marco divisório dos lotes rurais. Esse local foi batizado como Quatro Marcos e se tornou um ponto de encontro entre os sitiantes das redondezas (Bordin, 2018, pp. 30-31).

Num desses encontros nos Quatro Marcos, discutiram sobre a importância de ter uma escola para seus filhos, pois em 1966 já havia várias famílias no local e, com isso, a necessidade de oferecer estudo aos filhos tornou-se questão de primeira ordem. Assim, segundo Bordin (2018), Miguel Nascimento doou o terreno para construção da escola, a princípio nomeada de Escola Rural Mista Duque de Caxias. Assim,

Foi ao lado dessa encruzilhada de picadas, partindo dos Quatro Marcos, que abriram a clareira para construir a escolinha para atender as crianças dos sitiantes e famílias que chegavam [...]. Houve uma pequena festa de inauguração da escola. Era o dia 15 de junho de 1966. E os quatro marcos era apenas uma referência de localização de terras e da escolinha (Bordin, 2018, p. 35).

Essa instituição escolar foi construída em sistema de mutirão pelos migrantes, utilizando o que eles tinham na mata que os rodeava: madeira revestida de barro. "Ela tinha lousa e mesa de tábuas rústicas e os bancos eram fincados no chão" (Bordin, 2018, p. 38).

Inicialmente, a aula foi ministrada por Francisco Paulo de Brito, que logo abandonou a incumbência e interrompeu as aulas. No ano seguinte, a escola reabriu com 30 alunos, de $1^{\text {a }}$ a $4^{\text {a }}$ séries numa classe multisseriada, sob a regência de Inivaldo Mila, tendo Maria Luiza como auxiliar. Em depoimento, Mila relata que "os pais das crianças ficaram sabendo que eu tinha estudo e me convidaram para dar aulas; eu fiquei surpreso porque eu nunca pensei em dar aulas, mas aceitei” (Bordin, 2018, p. $38)$.

A imagem a seguir mostra a escola com as crianças e os professores: 
Figura 1 - Escola Mista Duque de Caxias.

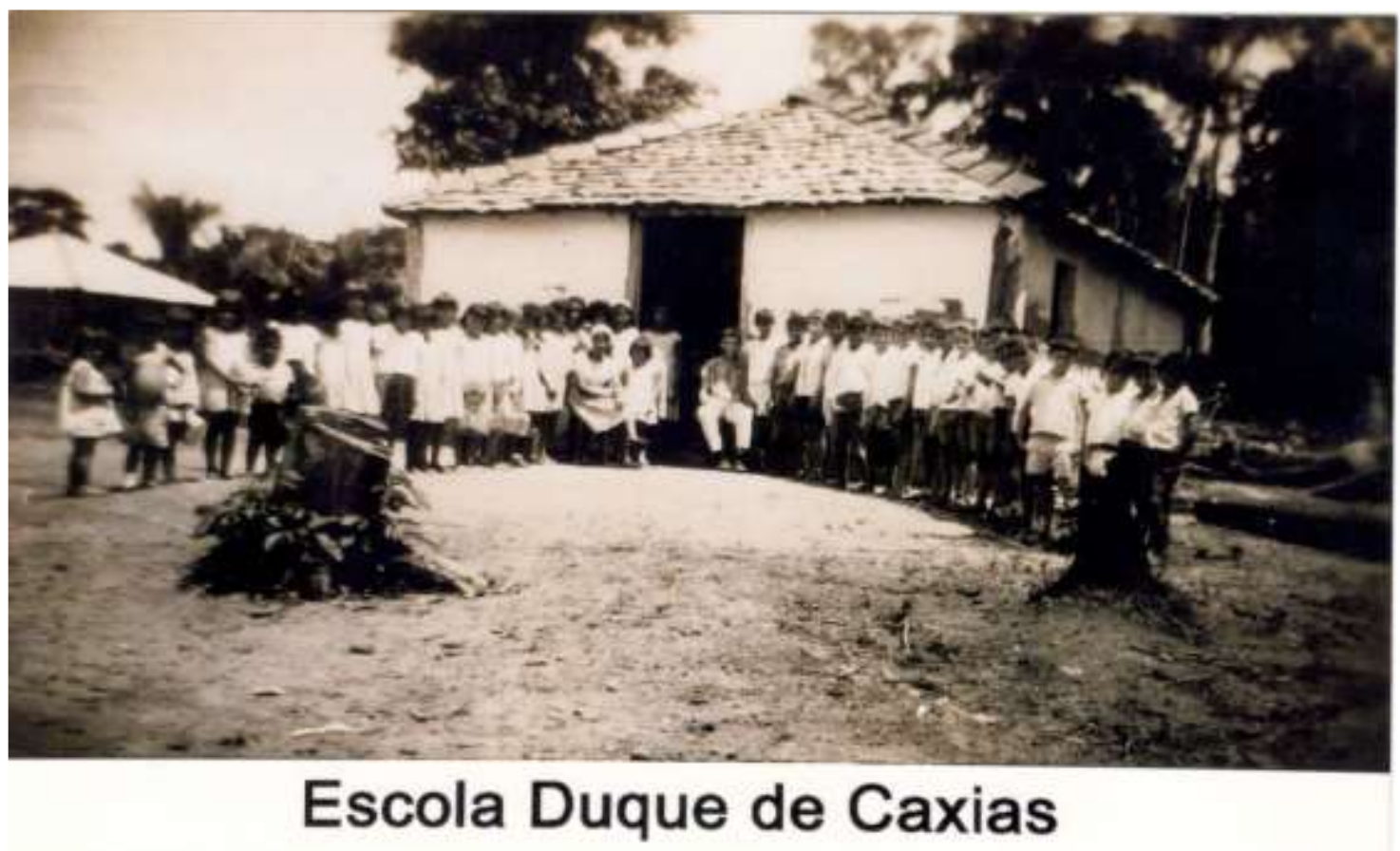

Fonte: Acervo particular de Hélio Paes Landin.

Percebe-se o número equitativo de meninas e meninos. Embora em meio a mata, as crianças se arrumavam para frequentar a escola. Ao centro, encontram-se os docentes Mila e Maria Luiza. Embora a imagem nos leve a supor a divisão das classes por sexo, a narrativa de Bordin indica a coeducação.

[...] como o número de crianças era muito grande, ele (Inivaldo Mila) chamou uma moradora de nome Maria Luiza Barbosa Alfredo para auxiliá-lo. E dividiram as séries. Mila ficou com as crianças da $3^{\mathrm{a}} \mathrm{e} 4^{\mathrm{a}}$ séries, no período matutino e Maria Luiza com as crianças de $1^{\mathrm{a}}$ e $2^{\mathrm{a}}$ séries, no período vespertino. [...] As matérias lecionadas eram língua portuguesa, matemática, ciências e educação moral e cívica. Tudo com ênfase na leitura e escrita (Bordin, 2018, p. 38).

Em áreas de colonização recente era muito comum a comunidade escolher dentre os migrantes aquele que havia estudado um pouco mais para ser professor das crianças, até que o local se desenvolvesse e professores formados se interessassem em migrar para as novas cidades ${ }^{4}$. No caso de Inivaldo, é importante destacar que ele investiu na formação docente em um curso de férias em Cáceres antes de entrar em sala de aula em 1967.

O Curso de Férias para docentes foi criado pelo governador Fernando Corrêa da Costa que expunha sua preocupação com o ensino ministrado pelos professores leigos nas escolas do estado. Era oferecido em várias cidades onde estudavam os "[...] ensinamentos de português, aritmética, geografia, história, higiene etc.” (Mensagem, 1952, p. 27). Em 1963, o Curso de Férias era ofertado nas seguintes cidades: Aquidauana, Cáceres, Campo Grande, Corumbá, Cuiabá, Dourados Guiratinga e Três Lagoas (Mensagem, 1963, p. 160).

Participar desse curso de férias tornou-se uma ação necessária para que o jovem colono Inivaldo Mila, recém-chegado numa área de colonização recente e tendo estudado até a $4^{a}$ série primária, pudesse atuar como professor em 1967 na Escola Rural Mista Duque de Caxias no povoado de Quatro Marcos. 
A exigência do curso de férias é uma prática reveladora de uma preocupação em âmbito nacional em que o país vivenciava no início dos anos 60 do século XX. Era preciso preparar professores para enfrentarem o desafio de ensinar, haja vista que, no início da década de 1960, cerca de $45 \%$ dos professores que lecionavam no ensino primário no Brasil não tinham formação para exercerem a função, ou seja, eram professores leigos. Neste cenário o curso de férias foi criado como curso preparatório para professores leigos e ocorria nos meses de janeiro, fevereiro e julho, isto é, durante as férias escolares (Amorin, 2013, pp. 45-47).

No estado de Mato Grosso, no início dos anos 1960, a porcentagem geral de professores leigos atuando no ensino primário era superior à média nacional, pois, em 1962, mais da metade dos professores que lecionavam não tinham formação para o cargo:

Os governantes mato-grossenses procuravam em 1962, com as prerrogativas consolidadas no I Congresso de Educação de Mato Grosso, elevar o nível de formação dos professores ao determinar que os leigos somente exerciam suas funções através da apresentação a uma comissão especial, do certificado de habilitação. Apesar da exigência desse certificado por parte da Secretaria de Educação e Saúde, mais de 60\% dos professores que atuavam em Mato Grosso eram leigos, ou seja, não dispunham de formação necessária para atuação no magistério. [...] esses docentes eram considerados um problema para o estado [...] (Amorim, 2013, p. 50).

Nos deparamos, então, com a situação calamitosa que afligia a educação no estado de Mato Grosso, pois $60 \%$ dos professores que lecionavam no ensino primário não eram capacitados para esta prática. Todavia, a falta de professores capacitados não era o único problema vivenciado no estado de Mato Grosso. Isto porque não só faltavam escolas, mas também muitas das que estavam em funcionamento tinham péssimas condições. Em relação às escolas rurais, a situação era ainda pior:

Numa breve incursão sobre a temática da história da escola rural brasileira podemos verificar que o professor, conforme a ausência de políticas públicas, era o responsável por todas as ações da escola rural. No Brasil, desde o início do período republicano, a educação urbana é a única assistida pelo poder público. A educação rural é abandonada à própria sorte. Em Mato Grosso, essa mesma prática encontrou eco, mesmo sendo observado que até 1970, a maior parte da população, residia na Zona Rural (Oliveira, 2009, p. 121).

As considerações do autor revelam o descaso do poder público com escolas rurais que, em consequência disso, enfrentavam toda uma gama de dificuldades com a falta de investimento em infraestrutura, sobretudo em áreas de colonização recente. A exemplo de São José dos Quatro Marcos e de tantas outras colônias, os construtores da primeira escola do povoado foram os próprios moradores, contando apenas com os materiais encontrados no cenário: a madeira e o barro. Desta forma, a situação da escola foi alvo de críticas pelo Correio Cacerense de 22 de março de 1970.

[...] problema cruciante desalegra as crianças estudiosas daquela localidade [...] aquelas crianças estão sendo desestimuladas ao estudo pelo fato de que na escola mista de São José dos Quatro Marcos não há carteiras para acomodar nem um aluno, quanto mais seus 137 oficiais. O senhor Edevaldo Muler, encarregado daquele estabelecimento, faz um apelo às autoridades competentes para que seja solucionado o problema, conquanto as aulas são assistidas de pé, causando evidentemente um estado psicológico contrário ao estudo [...] (Mato Grosso, 1970, p. 2).

O artigo expõe o abandono vivenciado pelos alunos de Quatro Marcos e esta não foi a única matéria a abordar as carências da educação no campo em Mato Grosso. Outra matéria do mesmo jornal, com data de 25 de outubro de 1970, denuncia que, no então povoado de Salto do Céu, a cerca de 64 quilômetros de São José dos Quatro Marcos, uma professora vendia galinhas para comprar giz:

É lamentável a situação em que se encontra as escolas no interior do município, declarou à reportagem o Dr. Antônio Lopes Lins, ex-fiscal do Banco do Brasil e candidato a uma cadeira na Assembleia Estadual. Frisou que em Salto do Céu, "das 36 professoras que servem os estabelecimentos de ensino daquela próspera localidade, 19 já abandonaram suas escolas" e em goiabeiras numa escola feita pelos próprios colonos "a professora vende galinhas para comprar giz". Continuou dizendo que recentemente visitou três glebas no município e constatou que Cruzeiro d'Oeste, Tabuleta, Lucialva e Lagoa dos Patos não possuem escolas, enquanto os moradores de Rio Branco vêm um bonito prédio, doado 
pelo governo com suas portas cerradas pela falta de professoras. Terminou o entrevistado dizendo que se eleito não ficará calado diante de tal situação (Mato Grosso, 1970, p. 3).

A matéria publicada pelo jornal converge para a concepção de Oliveira (2009) quando afirmou que em Mato Grosso, nos anos 1970, "a educação rural é abandonada à própria sorte".

Assim sendo, em Mato Grosso, nos anos 60 e 70 do século XX, em áreas de colonização recente, as crianças, nos anos iniciais de reocupação da terra, contavam com a boa vontade dos colonos para custear sua educação, pois, na maior parte das vezes, eram eles próprios que construíam as escolas em meio a mata e convidavam entre eles alguém que tinha estudado um pouco mais, ou seja, até a terceira ou quarta série primária, para se fazerem professores onde o abandono do estado era reinante.

No povoado de Quatro Marcos, foi o senhor Zeferino José de Matos, um dos colonos, que custeou o salário do professor nos primeiros meses de funcionamento da escola (Bordim, 2018). Em Salto do Céu, numa escola construída pelos colonos, a professora tinha que se desfazer de um bem de sua propriedade para comprar giz. Em Tangará da Serra, a diretora de um grupo escolar pedia a colaboração dos pais para custear despesas da escola (Oliveira, 2009). Em Alta Floresta, a colonizadora dava os materiais e os colonos construíram várias escolas rurais em meio a mata (Perim, 2015). Esta era a situação imposta às crianças que se deslocavam com seus pais para áreas que estavam sendo reocupadas nos anos 1960 e 1970 no estado de Mato Grosso.

Outra questão apontada pela matéria do Correio Cacerense refere-se ao fato de que, em Salto do Céu, as professoras estavam abandonando as salas de aula. Das 36 professoras 19 já haviam deixado suas cadeiras e, em Rio Branco, cerca de 15 quilômetros de Salto do Céu, uma escola estava fechada por falta de professores. Tal situação, ao que parece, se dava por falta de pagamento por parte do governo estadual. Observamos isso quando analisamos um contrato da Secretaria de Educação, Saúde e Assistência Social do município de Cáceres ${ }^{5}$ e de uma professora que lecionou na Escola Rural Mista de São José dos Quatro $\operatorname{Marcos}^{6}$ em 1972.

\footnotetext{
${ }^{5} \mathrm{O}$ município de Cáceres era responsável por administrar todas as escolas dos diversos povoados que existia em seus arredores. Ao longo de toda a década de 1970, esses povoados foram se emancipando e dando origem a diversos municípios, dentre eles: São José dos Quatro Marcos, Mirassol d'Oeste, Araputanga, Jauru, Rio Branco, Salto do Céu, Lambari d'Oeste.

${ }^{6}$ A primeira escola de São José dos Quatro Marcos chamava, em seus primeiros dois anos de funcionamento, Escola Rural Mista Duque de Caxias e, posteriormente, quando o nome do povoado se fixou como São José dos Quatro Marcos, essa escola foi renomeada por Escola Rural Mista de Quatro Marcos.
} 
Figura 2 - Contrato de professor.

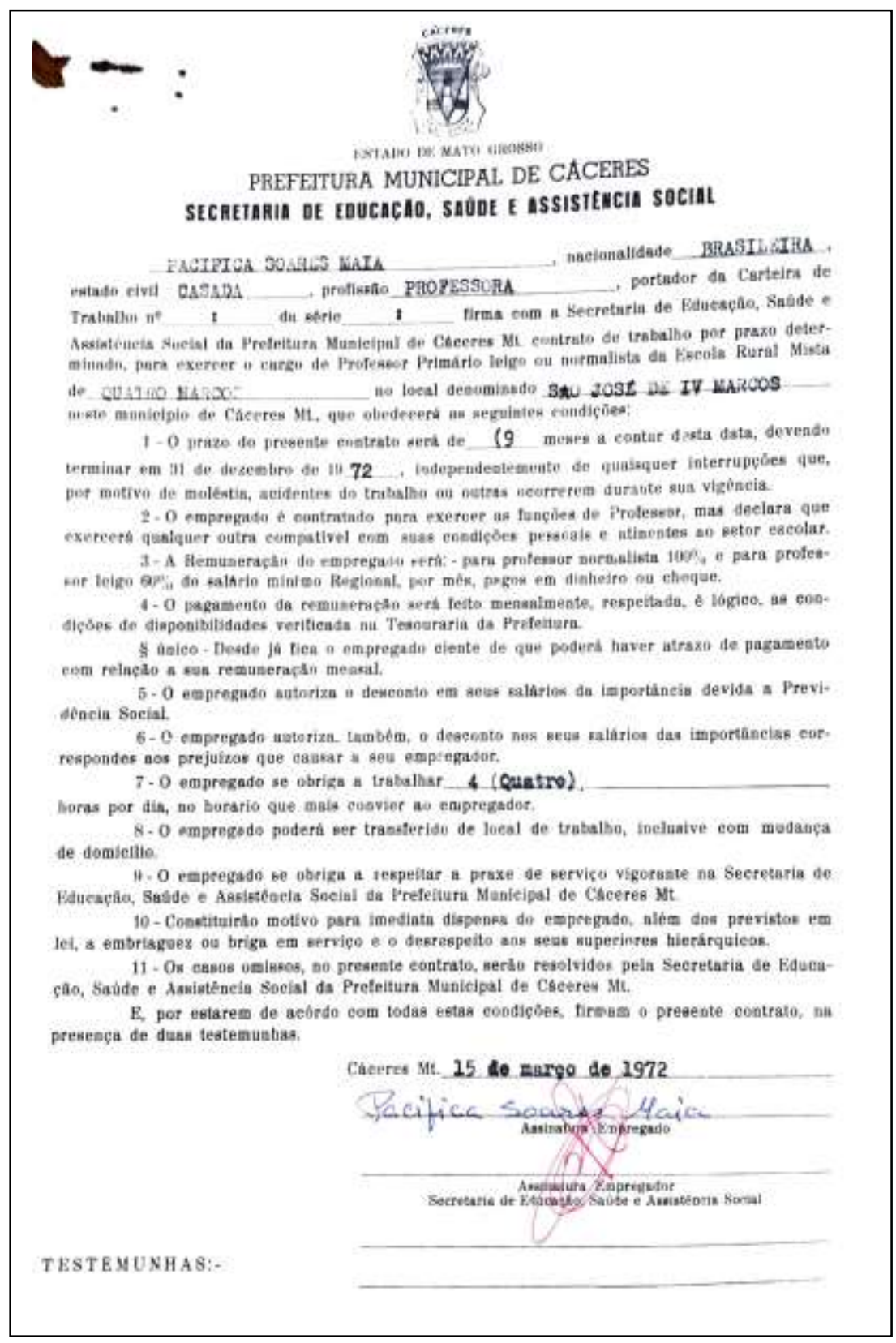

Fonte: Arquivo Público de Cáceres-MT.

Neste contrato, em seu artigo $4^{\circ}$, é abordado que há uma intenção de pagar o professor mensalmente, porém, desde que haja recursos públicos para tal. Como se não bastasse esse artigo, ainda fizeram questão de inserir um parágrafo único que ressalta que "[...] fica o empregado ciente de que poderá haver atrazo de pagamento em relação à sua remuneração mensal". Com esta prática, a prefeitura de Cáceres se isenta de maiores responsabilidades por atraso de pagamento, afinal o professor concordou em trabalhar em sob tais condições.

Diante dessa situação, supomos que os pagamentos não eram regularmente efetuados e, por conta disso, as professoras desistiam do ofício de ensinar, fazendo com que as crianças ficassem fora dos bancos escolares.

Tornar-se professor em áreas de colonização recente em Mato Grosso, onde não havia a infraestrutura mínima para o funcionamento de uma escola, ser mal remunerado e trabalhar sem saber quando iria receber seu salário era enveredar-se rumo à necessidade de improvisar, assim como um saltimbanco, abordado por Certeau (1994), que precisa agir com astúcia e esperteza 
para fazer-se professor em condições desfavoráveis e sobreviver com a possibilidade eminente de ausência de recursos ao final do mês, mesmo tendo cumprido com todas as suas obrigações.

\section{Considerações Finais}

Foi no contexto de chegada de migrantes, sobretudo paulistas, a terras ainda em vegetação nativa, distante de recursos médicos e de escolas estabelecidas, que homens e mulheres reinventaram seu cotidiano para enfrentar as dificuldades e para permanecer na área adquirida. Cabe ressaltar que esse fato se deu nos anos de 1960, quando os demais estados do país viviam em situação de transformações em diferentes aspectos: culturais, sociais e políticas.

Naquela realidade, a escola se tornou prioridade para garantir a permanência em áreas de reocupação recente, pois, sem oferecer educação escolar aos filhos dos migrantes, as famílias não permaneceriam em suas terras. Por isso, não mediram esforços para erigi-la em meio a floresta.

Viver numa área de colonização recente era algo penoso para os agricultores que se deslocavam para terras matogrossenses nos anos 1960 e 1970, para os seus filhos que estudariam em escolas improvisadas e sem os recursos das escolas de estados mais desenvolvidos e para aqueles que aceitavam o desafio de se fazerem professores em condições calamitosas, muitas vezes sem ter ao menos concluído o curso primário.

Contudo, ainda há muito o que pesquisar e descobrir acerca da primeira escola de São José dos Quatro Marcos, além de desvelar os movimentos sociais que a erigiu e a sua cultura escolar. Este é, portanto, o desafio desta pesquisa.

\section{Referências}

Amorin, R. P. (2013). Professoras Primárias em Mato Grosso: trajetórias profissionais e sociabilidade intelectual na década de 1960. Dissertação (Mestrado em Educação) - Instituto de Educação. Universidade Federal de Mato Grosso, Cuiabá.

Amorin, R. P. (2019) O curso de treinamento de professores leigos: profissionalizações e representações da docência em Mato Grosso (1963-1971). Tese (Doutorado em Educação) - Faculdade de Educação, Universidade Federal da Grande Dourados, Dourados.

Assis, R. M. (2012). A educação brasileira durante o período militar: a escolarização dos 7 aos 14 anos. Revista: educação em perspectiva, 3(2), 320-339.

Beck, K. M. K. (2015). Vivências e Memórias: A cultura escolar da Escola Rural Mista Municipal Santo Antônio em Tangará da Serra - MT (1965-1983). Dissertação (Mestrado em Educação) - Instituto de Educação, Universidade federal de Mato Grosso, Cuiabá.

Benito, A. E. (2007). Aprender pela experiência. In Benito, A. E. A escola como cultura: experiência, memória e arqueologia. (pp. 29-106). Editora Alínea.

Certeau, M. (1994). A invenção do Cotidiano I-Artes de fazer. Petrópolis: Vozes.

Corsetti, B. (2006). A análise documental no contexto da metodologia qualitativa: uma abordagem a partir da experiência de pesquisa do Programa de Pósgraduação em Educação da 16 Unisinos. UNIrevista, 1(1), 32-46. http://www.unirevista.unisinos.br/ pdf/Art\%2005\%20BCCorsetti.pdf.

Heinst, A. C. (2003). Pioneiros do século XX. Memória e relatos sobre a ocupação da cidade de Mirassol d' Oeste. Dissertação (Mestrado em História) Instituto de Ciências Humanas e Sociais, Universidade Federal de Mato Grosso, Cuiabá.

Joanone Neto, V., \& Pallota, F.P. (2013). Do sertão à fronteira, diferentes possibilidades metodológicas do uso de periódicos aplicadas ao estudo de casos pelo interior do Brasil. Revista eletrônica Documento/Monumento, 8, 36-49.

Lei $\mathrm{N}^{\circ}$ 4.024, de 20 de dezembro de 1961. https://www2.camara.leg.br/legin/fed/lei/1960-1969/lei-4024-20-dezembro-1961-353722-publicacaooriginal-1pl.html.

Lins: Professora vende galinhas para comprar giz. (1970, October 25th). Correio Cacerense, (186).

Mato Grosso. (1952). Mensagem do presidente do Estado a Assembleia Legislativa de Mato Grosso. Arquivo Público de Mato Grosso - APMT, Cuiabá.

Mato Grosso. (1963). Mensagem do presidente do Estado a Assembleia Legislativa de Mato Grosso. Arquivo Público de Mato Grosso - APMT, Cuiabá.

Perin, C. L. (2105). Escola, Colonização e Formação do Colono: História e Memórias da Terra Prometida de Alta Floresta - MT (1976-1976-1982). Dissertação (Mestrado em Educação) - Instituto de Educação, Universidade Federal de Mato Grosso, Cuiabá.

Oliveira, C. E. (2008). Tangará da Serra: uma história de colonização privada. In Barrozo, J. C. (Org.) Mato Grosso: do sonho à utopia da terra. (pp. 181-204). EdUFMT. 
Research, Society and Development, v. 10, n. 12, e423101220612, 2021

(CC BY 4.0) | ISSN 2525-3409 | DOI: http://dx.doi.org/10.33448/rsd-v10i12.20612

Oliveira, C. E. (2009). Migração e escolarização: história de instituições escolares de Tangara da Serra - Mato Grosso - Brasil (1964-1976). Tese (Doutorado em História) - Universidade Federal de Uberlândia, Uberlândia.

Oliveira, C. E. (2017). Fronteiras diversas em regiões de colonização recente de Mato Grosso: Tangará da Serra, Campo novo dos Parecis e Sapezal. Revista História e Diversidade, 9(1), 74-95.

Rohden, J. B. (2012). A Reinvenção da Escola: Histórias, Memórias e Práticas Educativas no período colonizatório de Sinop-MT (1973-1979). Dissertação (Mestrado em Educação) - Instituto de Educação, Universidade Federal de Mato Grosso, Cuiabá.

Sá, E. F., Perin, C. L., \& Beck, K. M. (2007). Escolarização da infância em cidades de colonização recente de Mato Grosso. Revista Diálogo Educaional, 17(51), 61-79.

Sanfelice, J. L. (2007). História das Instituições Escolares. In Nascimento, I. M. et al. (orgs.). Instituições escolares no Brasil: conceito e reconstrução histórica. HISTEDBR; UNIO; UEPG

São José dos Quatro Marcos: alunos estudam de pé. (1970, March 22nd). Correio Cacerense, (126). 